\title{
دور الجمعيات والمؤسسات الأهلية في هجال رعاية الأشخاص ذوي الإعاقة
}

\author{
إعداء \\ أ.د/ محمد المري محمد إسماعيل \\ أستاذ علم النفس التزبوي \\ مدير مركز القياس والتقويم-جامعة الزقازيق- مصر المري
}

همقدهة:

شهدت الفترة الأخيرة اهتماماً منزايداً بمشكلة ذوي الإعاقة، وذلك في ضوء الاهتمامات الإقليمية والعالمية والتي ساهمت في توجيه العديد من السياسات الحكومية نحو هذه المشكلة لتحقيق المساعدة لهذه الفئات الخاصة. ولقد تفاقمت مشكلة ذوي الإعاقة في أغلب المجتمعات سواء كان ذلك في الدول النامية أو المتقدمة، والسبب في هذا التفاقم هو نزايد أعداد ذوي الإعاقة من جهة وقصور المجهودات الموجهة للحد

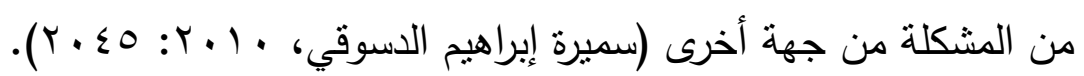

وتبعاً لزيادة أعداد ذوي الإعاقة في المجتمع المصري فإن النظرة إليهم قد تطورت في السنوات الأخيرة، وأنثئ العديد من مؤسسات الرعاية الاجتماعية لرعاية ذوي الإعاقة في جميع القطاعات. فالإعاقة سواء كانت جسمية أو حسية أو عقلية أو اجتماعية تحول بين استفادة ذوي الإعاقة من الخبرات التعليمية والمهنية التي يستطيع الفرد العادي الاستفادة منها، ولذا فهو في أثند الحاجة إلى نوع خاص من البرامج

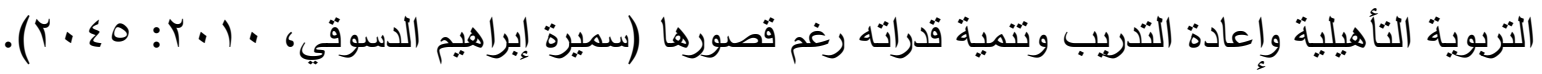
ولذا فقد شهد القرن الحالي اهتماماً ملحوظاً برعاية ذوي الإعاقة وأصبحت الرعاية الاجتماعية لذوي الإعاقة من أهم البرامج التي تأخذ مكان الصدارة في العالم المتقدم والنامي على حد سواء بهدف التخطيط الواعي لإحداث التغيير المقصود لإيجاد التوافق بين أداة الإنسان لأدواره ووظائفه الاجتماعية وبين بيئته التي يعيش فيها وليدرك الإنسان ذوي الإعاقة أنه يملك قدرات وطاقة هائلة إذا ما تم تدريبه وتوجيهه

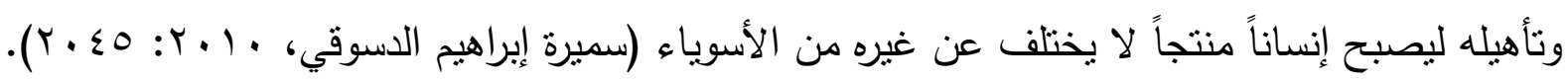
وتؤكد حقائق ومعطيات الواقع المعاصر أننا نعيش بالفعل عصرًا غير مسبوق في تسارع إيقاعاته، وتعدد وتتوع تغيراته، وعمق تأثنراته وتداعياته، عصرًا يحمل العديد من المشكلات والقضايا في كل الميادين والمجالات وعلى كل الجبهات، وهي في مجملها تشكل تحديات تواجه كافة المؤسسات وتفرض التعامل

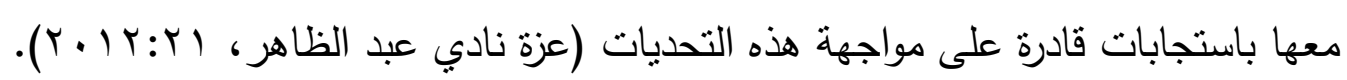
ومع مرور عالمنا بتلك التغيرات المتلاحقة واجتياح ثوره المعلومات لكل ركن من أركانه، وما يفرضه ذلك من حتمية إحداث تغييرات جذريه في التتظيمات المجتمعية الحالية، وما بتطلبه من ضرورة تتميه روح التعاون بين كل فئات المجتمع على اختلاف مؤسساته، فإننا نجد أن تفعيل دور تلك المؤسسات وبخاصة 
الجمعيات الأهلية وإشراكها في حل القضايا والمشكلات المجتمعية أصبح جزءا أساسيا في فلسفه المجتمع وأصبح للجهود الأهلية أهميتها في التتمية والتقدم وأصبحت الجمعيات الأهلية مكون رئيسي من مكونات المجتمع المدني ، ولكونها الأكثز انتشارا والأسرع حركه وإنجازًا ومرونة والأقل كلفة في معالجة المشكلات المجتمعية، فإن وجود الجمعيات الأهلية أصبح أمرا ضروريا ومرغوبًا فيه (عزة نادي عبد الظاهر، $\cdot(r): r \cdot 1 r$ إن العمل الأهلي أو القطاع الثالث كما تسميه منظمات الأمم المتحدة، يحتل مساحة كبيرة من العمل الاجتماعي والاقتصادي في البلدان المتطورة، ويشكل جزءا "عضويا" فاعلا في ديناميتها ومنظورها للنطوير المجتمعي والتغيير الاجتماعي- السياسي (كامل مهنا، ل . . ب: ؟). ومن بين تلك المؤسسات الجمعيات الأهلية التي تعد أحد الركائز الأساسية للتمية في ظل مجتمع الاقتصاد الحر بجانب الدولة والقطاع الخاص، وهو ما أدى إلى التزايد المطرد في عددها، حيث أصبحت الجمعيات الأهلية الأقدر على الاتصال بالقواعد الثعبية الدنيا بحكم طبيعتها التطوعية الثعبية، ومن ثم الأقدر على تلمس حاجاتها ومشكلاتها وتمنل تطلعاتها وتعبر عنها، ومن ثم هي الأقدر على تحديث وتطوير خدمات الرعاية الاجتماعية في مجالاتها المختلفة ومنها مجال رعاية ذوي الإعاقة (سميرة إبراهيم

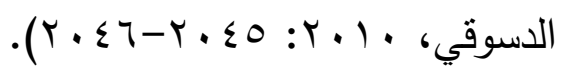

ومن هنا كان الاهتمام بتنشئة الأطفال ورعايتهم منذ طفولتهم المبكرة هو الوسيلة المنلى لتحقيق التتمية البشرية المادية. ولا يقتصر ذلك على الأطفال العاديين، بل إن الأطفال ذوي الإعاقة يمكن أيضًا استثمار قدراتهم عن طريق الاهتمام بتربيتهم، والاستفادة من إمكاناتهم إلى اقصى حد ممكن ليساهموا في بناء المجتمع ورفاهيته. فاهتمام المجتمع بتربية الأطفال ذوي الإعاقة ورعايتهم منذ وقت مبكر يحولهم في المستقبل إلى مواطنين منتجين لا يعيشون عالة على ذويهم، بل يسهم كل قدر استطاعته في تتمية

$$
\text { المجتمع (طارق حسن صديق، r . . r: r). }
$$

وتطمح بنى المجتمع المدني ومنها الهيئات الأهلية إلى تحقيق المزيد من الديمقراطية في المجتمعات والمزيد من الضمانات لحقوق الإنسان. ومن أهم المظاهر البارزة في العقود ما قبل الأخيرة من القرن الماضي، الاهتمام بقضية ذوي الإعاقة. كما أن التطور الإيجابي في مفاهيم حقوق الإنسان، من ناحية تانية قد سلطت الضوء نحو الانسان ذوي الإعاقة، دن قبل الحكومات، ومن قبل بنى المجتمع المدني

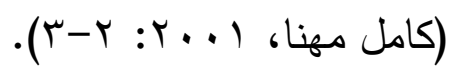
وتعتبر مشكله الإعاقة أحد الأخطار الرئيسية التي تواجه العالم في الوقت الحاضر وذلك نظرا لما تحمله من تدمير للكيان الانسانى والنفسي والاجتماعي وعدم مواجهتها المواجهة العلمية يجعل الأشخاص ذوي الإعاقة في صراع مع أسرته ومع المجتمع مما بؤدى إلى نوبات عنف ضده وضد المجتمع. وبالتالي فقد ظهرت الحاجة إلى إثراك الجهود الأهلية في المشكلات المجتمعية باعتبارها أكثر أحساسا باحتياجات 
الأفراد والمجتمعات المحلية، إلى جانب أنها تمتاز بالمرونة في أداء وظائفها، وتهدف إلى سد الفراغات

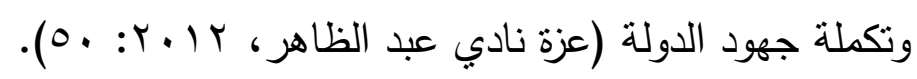

وأدت التغيرات الاجتماعية والاقتصادية والثقافية التي شهدتها المجتمعات الإنسانية المعاصرة سواء على المستوى العالمي أو المحلي في الحقب الأخيرة إلى انتشار الدعوات التي تدعم قيم العمل التطوعي والإعلاء دن شأن القيم الجماعية والتعاونية وتفعيل دور المنظمات غير الحكومية، وزيادة دورها في المجالات المختلفة للتنمية. فالجمعيات الأهلية تقوم بدور رئيسي في توفير العديد من أوجه الرعاية وبرامج التتمية بل أن هذا الدور يتزايد نظرًا لتراجع دور الدولة في بعض المجالات وتخليها بعض الثئ عن بن كونها دولة رفاهية. ولقد انعكس ذلك على اهتمامها بقضايا جديدة عليها نسبيًا ومن أمثلتها البيئة، حماية حقوق المستهلك، التتمية في الأحياء الثعبية الفقيرة، نوعية الخدمات الصحية والتعليمية، عمالة الأطفال، ولهال

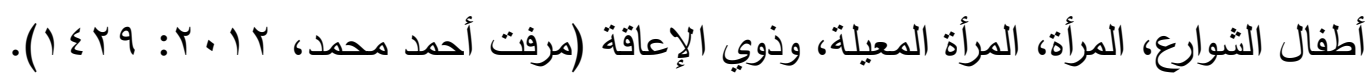
ولا يكاد مجتمع من المجتمعات الإنسانية يخلو من وجود أفراد ذوي الإعاقة، إلا أن الفرق يظهر في إنهاء طبيعة نظرتها وتعاملها مع هذه الفئة من فئات المجتمع فلكلٍ خصوصيته التاريخية والحضارية، ومنظومة القيم والمعايير الاجتماعية التي تحكم تصرفات أفراده، وتحدد نظرتهم إلى مختلف أمور الحياة (عزة نادي

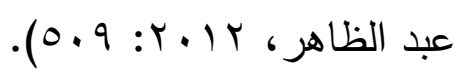

وقد نال مجال رعاية ذوي الإعاقة باهتمام بالغ في السنوات الأخيرة سواء من ناحية الدراسة العلمية أو من ناحية التقدم التكنولوجي، ويرجع ذلك إلى الثعور المتتامي في المجتمعات المختلفة بأن الثخص ذوي الإعاقة الحق في الحياة كغيره من أفراد المجتمع حسب قدراته وإمكانياته. وبدأ الاهتمام بهم في نهاية

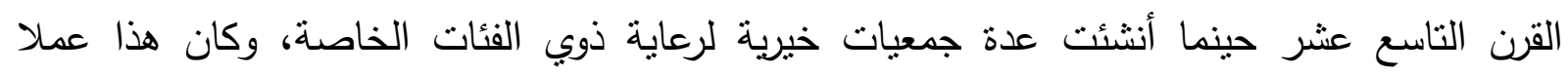
اجتهاديًا بجهود أهلية أو شبة حكومية لا تستند على قانون حتى منتصف القرن العشرين. إذًا فالجمعيات الأهلية تقوم على تدعيم وتقوية المشاركة والتكامل في المجتمع (مرفت أحمد محمد، ب ( • ب: . بـ ( ). فالجمعيات الأهلية هي الأسرع حركة والأكثر مرونة والاقل كلفة في معالجة مشكلات الحاضر ومواجهة تحديات المستقبل، فضلا عن أنها ترتكز في معظم أنشطتها على المبادرات التطوعية. حيث لا توجد قيود حقيقية على الخدمات التي تنتطيع الجمعيات الأهلية أن تقدمها، فهي تستطيع أن تقدم خدمات تعليمية وصحية وثقافية ودينية وعلمية، ويمكن أن تقدم هذه الخدمات لبعض أو كل فئات المجتمع. فهي قريبة من المجتمع تحاول استكثاف حاجات الفئات الضعيفة فيه، ثم تحاول القيام بالأنشطة التي تتولى إثباع هذه الحاجات إلى جانب الجهود الرسمية. وحيث إن الأطفال ذوي الإعاقة من أكثر الفئات الضعيفة في بالي المجتمع بحاجة إلى الحصول على الخدمات التربوبة والتعليمية، فقد تصدت بعض الجمعيات الأهلية في مصر لرعاية الأطفال ذوي الإعاقة باعتبارهم أحد مجالات نشاطها التي نص عليه القانون رقم (rr)

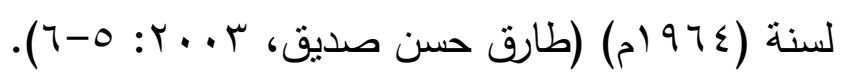


ولأن جهود الجمعيات الأهلية مصدرًا لا ينضب من الخيرات والطاقات والحوافز . ولأن تربية الطفل ذوي الإعاقة تحتاج إلى هذه الجهود. فإن الدراسة الحاليه تهتم بالتعرف على دور الجمعيات الأهلية في مجال رعاية ذوي الإعاقة، ومن ثم وضع رؤية مستقبلية لتفعيل دورها تجاه هؤلاء الفئة.

\section{مشاكلة الدراسة:}

أن الإعاقة ليست مسئولية الدولة وحدها وإنما هي مسئولية مشتركة بين الدولة والمجتمع بما فيه من مؤسسات اجتماعية متخصصة إضافة إلى مسئولية الأسرة والثخص ذوي الإعاقة نفسه وعلى جميع

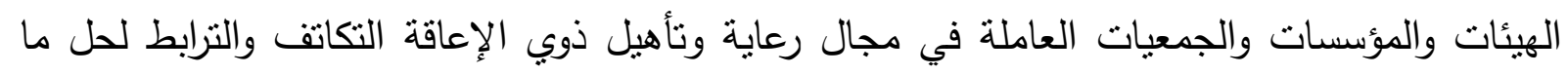
يواجه هذه الفئة من مشكلات والعمل على حلها ومطالبة كل جهة اختصاص بالعمل على دمج هذه الفئة

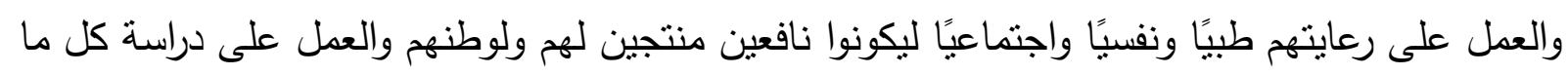

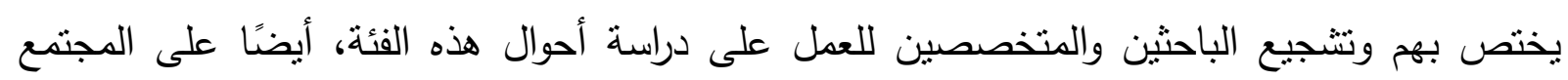

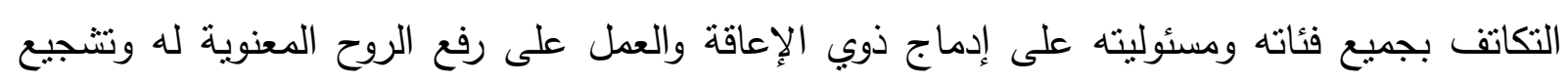
ودعم ما تبقى من قدرات لديه والاعتراف بهم داخل المجتمع المحيط وتحسين النظرة السلبية التي يعانون منها بالمجتمع والعمل على تشجيعهم ليكونوا عناصر بارزين نافعين لأنفسهم وللمجتمع، فعلينا جميعا هيئات ومؤسسات وجمعيات وإدارات ووزارات العمل على دمج هذه الفئة والاعتراف بكافة حقوقهم القانونية

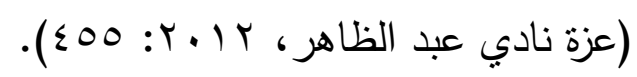
وتتعدد مؤسسات المجتمع التي تتعامل مع ذوي الإعاقة ويأتي على رأس هذه المؤسسات الجمعيات الأهلية التي بدأت تفرض نفسها كثريك أساسي في المجتمع، ومن هذا المنطلق تظهر أهمية إثراك

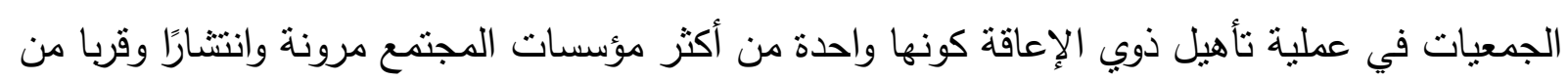
أفراده يضاف إلى ذلك ما يشهده العالم من تغيرات جراء العولمة وسياسات السوق الحرة وكل ما يحدث

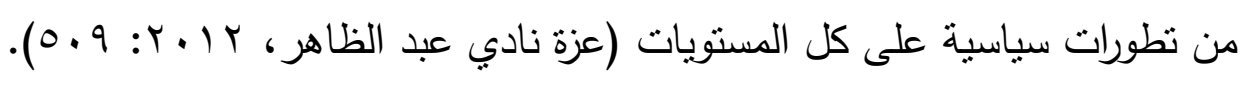

ومع وجود بعض الجمعيات الأهلية التي لها اسهامات واضحة في رعاية ذوي الإعاقة؛ فإن هذه الجمعيات تحتاج إلى دراسات علمية لإظهار هذه الإسهامات ومعرفة المعوقات التي تحول بينها وبين التوسع في تقديم الخدمات، وتحفيز الجمعيات الأخرى لتقديم مثل هذه الخدمات للتلاميذ ذوي الإعاقة (محمد أحمد

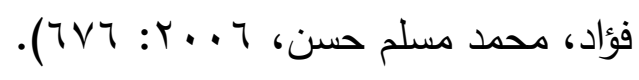

\section{ومن هنا تنتمثل مشنكالة الدراستة في الأسئالة النالية:}

ا ـ ما هية الجمعيات والمؤسسات الأهلية في مصر؟

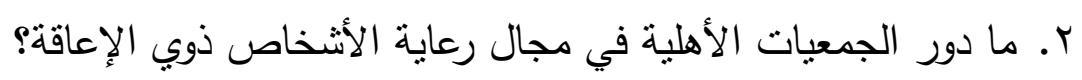

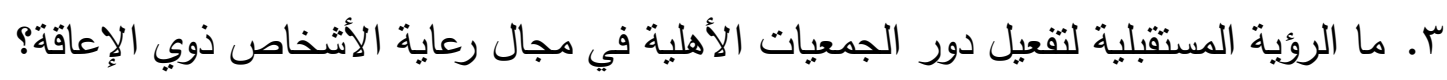




\section{أهداف الدراستة:}

تهدف الدراسة الحالية التعرف على ماهية الجمعيات والمؤسسات الأهلية في مصر ، وكذلك التعرف على دورها في مجال رعاية الأثخاص ذوبي الإعاقة. وأيضًا وضع رؤية مستقبلية لتفعيل دور الجمعيات الأهلية

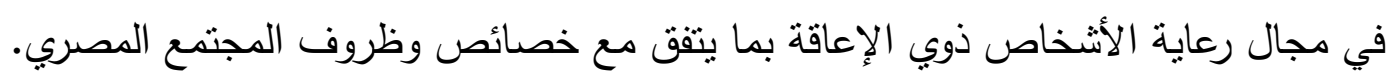

\section{أهميهية الدوراسة:}

1- أهمية دور الجمعيات الأهلية في المجتمع وبخاصة في الأونة الأخيرة وأهيتها في تخطيط وتقديم

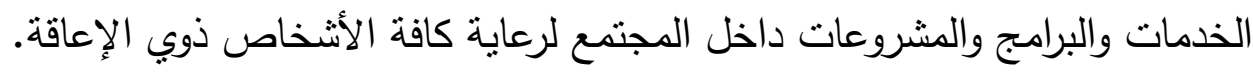

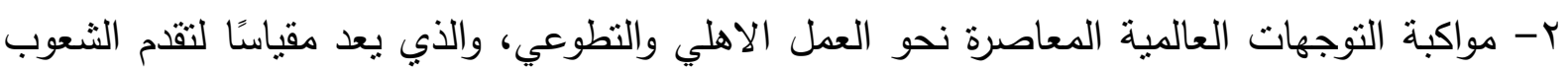
بما يعكسه من إدراك الأفراد لمسئولياتهم تجاه مجتمعاتهم.

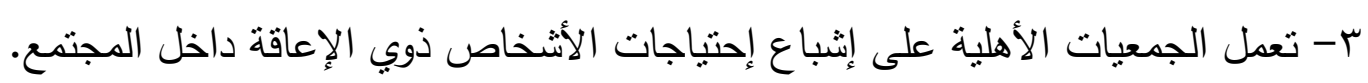

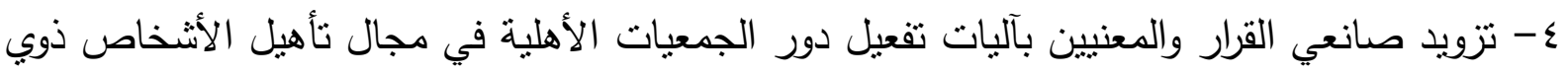

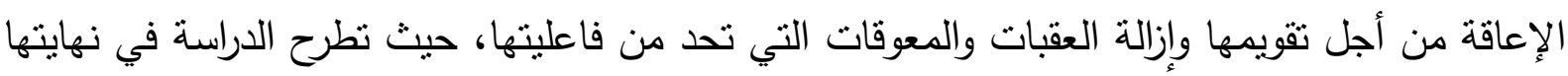

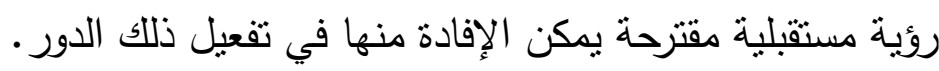
ه- إلقاء مزيدًا من الضوء حول ضرورة تفعيل دور الأشخاص ذوب الإعاقة وأسرهم وأفراد المجتمع تجاه الجمعيات الأهلية لتمكينهم من الحصول على المعلومات والمشاركة في اتخاذ القرارات ورقابة وتقويم الخدمات المقدمة من الجمعيات الأهلية في هذا المجال. 1- تعتبر قضية الإعاقة من أهم القضايا الإنسانية والاجتماعية والاقتصادية المطروحة على الإلى الساحة حيث إن لها أبعاداً تنربوية ووقائية وعلاجية. V- تتاولت الدراسة فئة من فئات الأطفال تحتاج إلى المزيد من الجهود لتوفير القية القدر الكافي من الخدمات التربوية لها، ألا وهي فئة الأطفال ذوبي الإعاقة. 1- الاهتمام الدولي بقضايا حقوق الإنسان والتي من بينها فئة ذوبي الإعاقة (حقوق ذوي الإعاقة)، حيث أن من حق ذوي الإعاقة أن يحصلوا على حقوقهم الإنسانية وتوفير الخدمات الصحية والاجتماعية والتربوية والتأهيلية اللازمة لهم، لكي يحدث لهم التوافق ان والكفاية الذاتية والاجتماعية والمهنية. 9- الاتجاه العالمي المتزايد نحو تفعيل دور القطاع النطوعي في التعليم بعامة والجمعيات والمؤسسات الأهلية بخاصة في رعاية ذوبي الإعاقة. 
- الجمعيات الأهلية: هي منظمات وجمعيات غير حكومية، مشهرة بوزارة التضامن الاجتماعي، وتخضع لإثرافها، وتتكون من جمعية عمومية ومجلس إدارة وعدة لجان وعاملين بها، وتعتدد

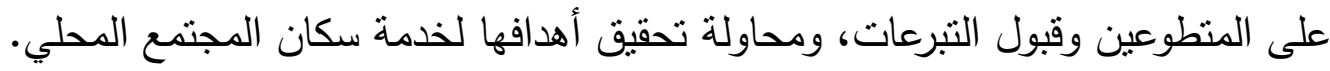
- الجمعيات والمؤسسات الأهلية لرعاية ذوي الإعاقة: أنها منظمات غير هادفة للربح نابعة لوزارة الثئون الاجتماعية قام الأهالي بإنشائها بهدف تقديم خدمات مختلفة لذوي الاحتباجات الخاصة الاصدية

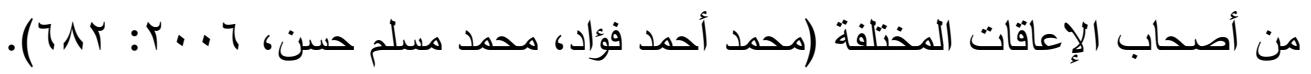
- الأثخاص ذوي الإعاقة: هم الأفراد الذين يعانون من سوء النوافق في الحياة، بحيث يعيق سوء

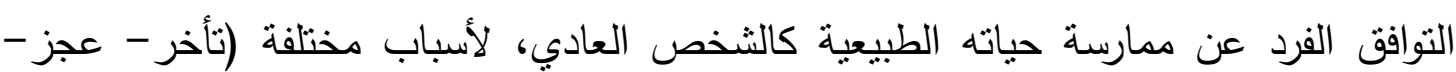

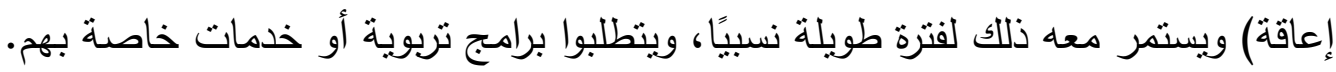

ويمكن تعريف الأثخاص ذوي الإعاقة: أيضًا بأنهم" أولئك الأفراد الذين ينحرفون عن المستوى العادي أو

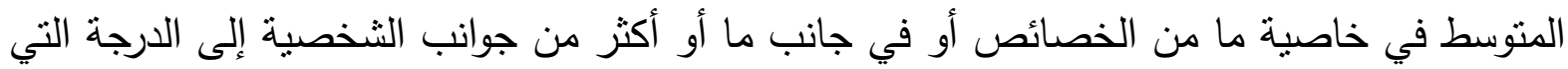

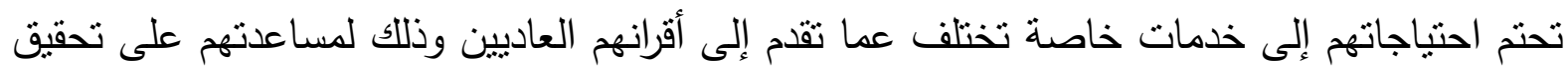

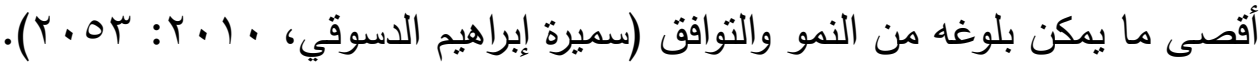

وفئات ذوي الإعاقة بمصر تتدرج تحت تسعة قطاعات هي كما يذكرها_(يوسف هاشم إمام،

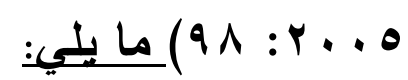

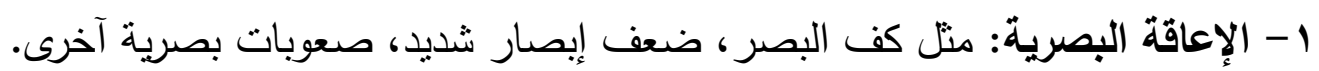
ץ- الإعاقات البدنية: منل بتز بالطرفين العلويين، وبالطرف العلوي الأيمن، وبالطرف السفلي الطبلي الأيمن،

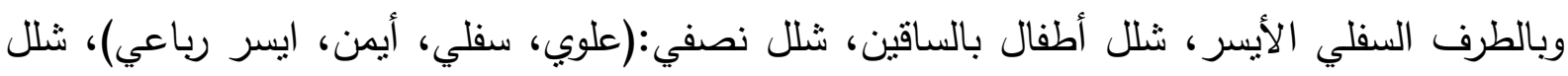
ثلاثي، شلل مخي، ضمور عضلات، تشوهات جسمية آخرى، إصابات بالعمود الفربي.

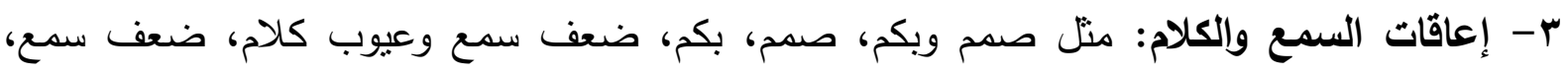

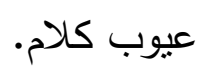
ـ - الإعاقات الذهنية: مثل التخلف العقلي بدرجاته الدختلفة، الأوتيزم، الاسبرجر .

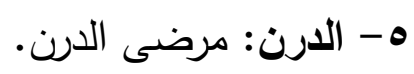

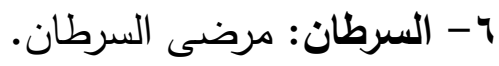

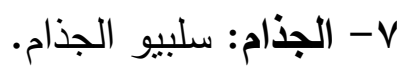
1- روماتيزم القلب: مرضى روماتيزم القلب. 


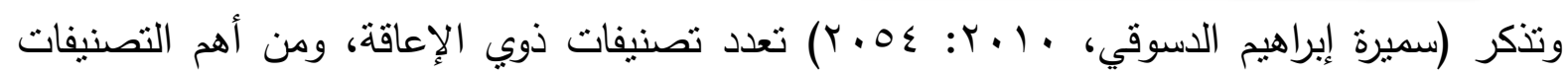
الثائعة الاستخدام في مجال دراسة ذوي الإعاقة كما ما يلي: ا - الإعاقات الجسمية: ويقصد بها الإعاقات التي تتتج عن قصور أو عجز في الجهاز الحركي، مثل:(الثلل الدماغي- شلل الأطفال- بتر أحد أطراف الجسم). ץ - الإعاقات الحسية: وترتبط هذه الإعاقات بحواس الإنسان وخاصة (حاسة البصر - السمع - النطق

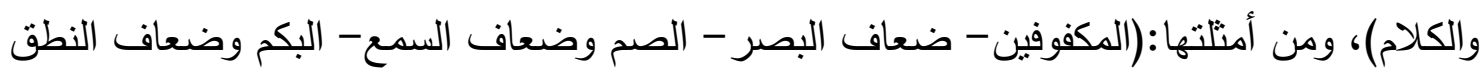

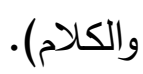
ץ- الإعاقات العقلية: وهم مرضى العقول وضعافها، ومن أمثلتها:(الفصام - البارانويا - ذهان الهوسوالاكتئاب- المعتوهون - البلهاء - المورون). ع - الإعاقات الاجتماعية: ويعتبر مفهوم الإعاقات الاجتماعية من المفاهيم الحديثة التي يطرحها بعض علماء الاجتماع والنفس والطب النفسي والاجتماعي وغيرهم إيماناً منهم بمدى ارتباط مفهوم الإعاقة بنوعية الحياة الاجتماعية والبيئية التي توجد في المجتمع ذاته. ه - متعددو الإعاقات( ذوي الإعاقات المتعددة): ويقصد بهذه الفئة من المعاقين الأفراد الذين يعانون من أكثر من إعاقة واحدة في نفس الوقت منل الثلل مع التخلف العقلي أو الإعاقات الحركية والسمعية والصم والبكم أو التخلف العقلي مع عيوب الكلام وضعف السمع والبصر وغير ذلك من إعاقات مزدوجة.

\section{وللإجابة على أسئلة الدراسة هن خلال همايلي:}

\section{السؤال الأول : ما هية الجمعيات والمؤسسات الأهلية في مصر؟}

تعد الجمعيات الأهلية بمثابة العمود الفقري للمجتمع المدني في مصر ، حيث تمثل قوة لا يستهان بها في المجتمع لما تقوم به من دور إيجابي في دعم العملية التعليمية بعامة وتلاميذ مدارس التربية الخاصة بخاصة، حيث إن رعاية هذه الفئة من التلاميذ تمثل ضرورة مهمة لهم ولمجتمعهم، باعتبارهم طاقة بشرية يمكن استثارها جيدًا إذا تم رعايتهم بصورة مناسبة مما يؤدي إلى عدم إهدار هذه الطاقات البشرية، ومما

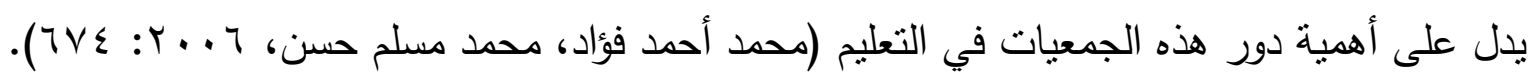
وقد نشأت فكرة العمل الاجتماعي التطوعي الخاص في شكل تتظيمات سعى الاهالي إلى تكوينها بهدف المساهمة في معالجة المشكلات الاجتماعية التي قد تعجز الحكومة عن حلها بشكل منفرد وقد بدأت في شكلها المنظم في مصر بقيام الجمعية الخيرية اليونانية في الإسكندرية في عام ابیام ثم ثتابعت الجمعيات ذات التخصصات والاهتمامات الأخرى في الظهور والعمل حتى بلغ عددها (70) جمعية قبل 
اشتعال ثورة 9 ا9 ام التي قامت كنتيجة جزئية للعمل الإيجابي لتلك المنظمات. ووفقًا للقانون رقم 101 هوه لسنة 999 (م فهناك خمسة مسميات للجهات المهتمة بالعمل الاجتماعي الأهلي هي الجمعية الأهلية،

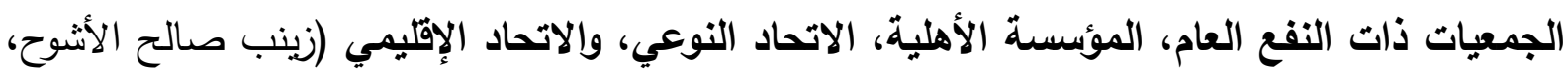
$\cdot(1 \leq: r \ldots$

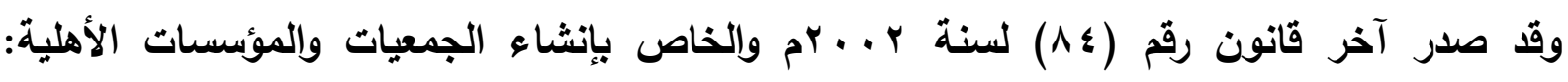
وتتضمن اللائحة التتفيذية له في احدى عشر بابا مكونا من (•1 ( ) مادة بالإضافة إلى النماذج الخاصة به. وتضمن الباب السابع عن (دور الإيواء) مادة (111) والتي تتص على "أن تعد دار للإيواء في مكان للإقامة الكاملة لفئة من الفئات المحتاجة للرعاية الاجتماعية أو الصحية أو التأهيلية أو التعليمية أو التربوية، وذلك في مراحل العمر المختلفة، ومنهم دور رعاية للأطفال العاجزين والمعوقين وضعاف

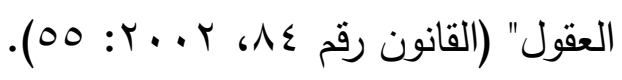

وهكذا نشأت فكرة الجمعيات الخيرية والمؤسسات الاجتماعية كتنظيمات أهلية قامت على ركيزة من رغبة الأهالي في التعاون لعمل الخير، وإحساسهم بالمشاكل الاجتماعية السائدة في مجتمعاتهم، وعجزت الحكومات عن مواجهتها بجهودها القاصرة، في وقت كان معظمها مشغولًا فيه بمواجهة قوة داخلية جعلتها

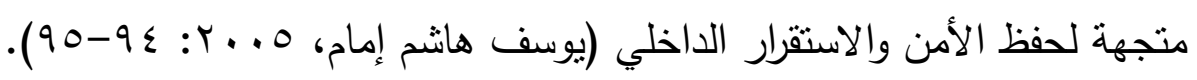

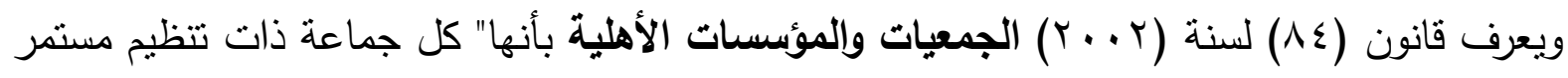
لمدة معينة أو غير معينة تتألف من أشخاص طبيعبين أو اعتباريين أو منهما معاً لا يقل عددهم في جميع الأحوال عن عشرة وذلك لغرض غير الحصول على ربح مادي. كما أنها المنظمات التي تشرف عليها وزارة الثئون الاجتماعية سابقًا (التضامن الاجتماعي)، والتي قام بها الأهالي بإنشائها في مجتمعاتهم نتيجة لشعورهم بأنها الوسيلة المناسبة لمواجهة ما يعانونه من احتياجات وما يواجهونه من مشكلات عن طريق توحيد الجهود الذاتية مع جهود المنظمات غير الحكومية

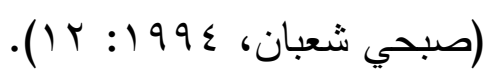

كما تُعرف بأنها جمعيات أو منظمات لا تهدف إلى الربح وتقدم خدمات إجتماعية وشخصية لأفرادها في جماعات سكانية مستهدفة وتؤسس عن طريق مساهمات تطوعية وخيرية ومساهمة بإعانات حكومية

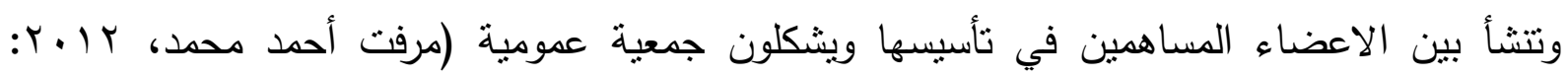


يذكر (محمود البخيت، ب . .r: T) أن الجمعيات الأهلية تعتمد في ممارسة اعمالها على مصادر التمويل

$$
\text { 1 - التبرعات والمنح التي تقدم إليها من الجهات الرسمية والأهلية. }
$$

$$
\text { r- الاتشراكات التي يساهم بها أعضاء الجمعية. }
$$

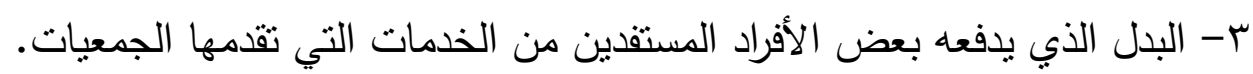
وبوجه عام فالتظظمات الدذكورة تقع تحت إثراف ورقابة وزارة التضامن الاجتماعي (الثئون الاجتماعية سابقًا) وعادة ما تحصل منها على دعم مؤقت حتى تستطيع الاستقال بمواردها الذاتية.

\section{وظائف الجمعيات الأهلية :}

تسعى الجمعيات الأهلية إلى سد الفجوة بين حاجات وتطلعات المواطنين وبين إمكانيات وموارد الدولة

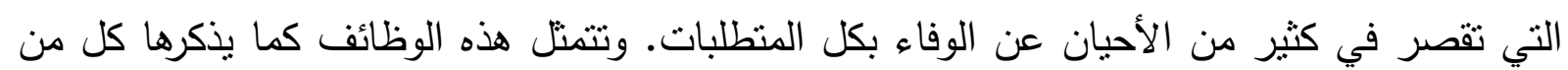

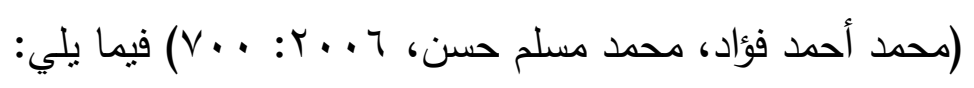

(1) النتشئة: وتعني ان مؤسسات الجمعيات الأهلية تعتبر أبنية مجتمعية يتعلم الفرد في جنباتها القيم

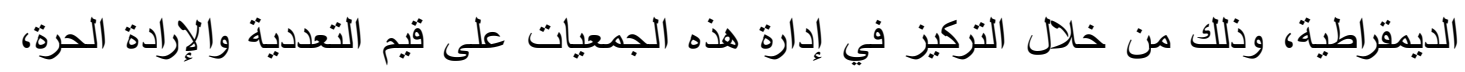
والإرادة السليمة للحوار، والمناقتنة في اختبار القيادات ومساءلتهم، والمشاركة في الانتخابات ترشيحًا وانتخابًا.

(r) التمثيل: نستطيع الجمعيات الأهلية أن تحشد جهود ومطالب الأفراد وتهذبها وتضفي عليها

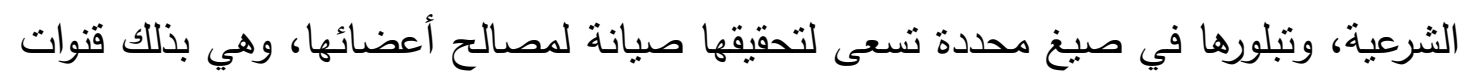
مشروعة للتعبير عن المطالب والحد من هيمنة البيروقراطية في المنظمات الحكومية.

\section{بعض السمات المميزة للجمعيات والمؤسسات الأهلية ومجالات وأنشطة عملها :}

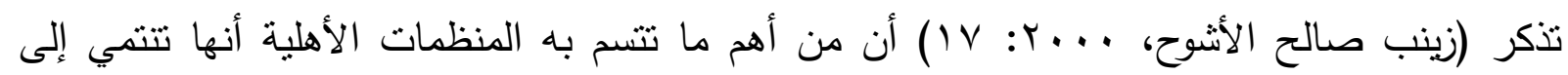

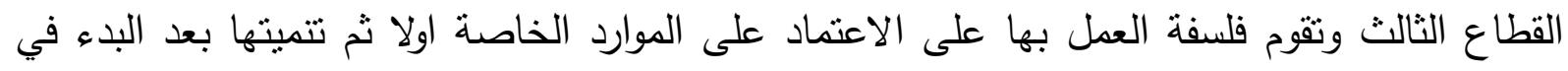

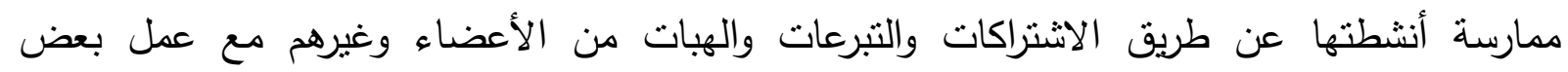

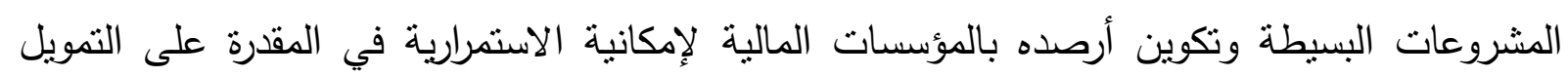

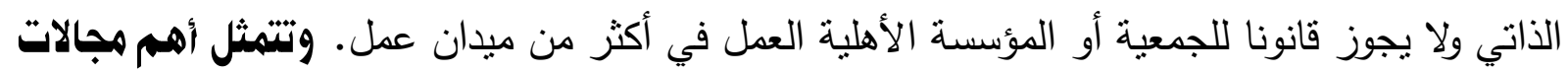




$$
\begin{aligned}
& \text { r- رعاية الاسرة. } \\
& \text { ع - رعاية الثيخوخة. } \\
& \text { 7- رعاية المسجونين. }
\end{aligned}
$$

ᄉ - تتمية المجتمعات المحلية.

$$
\text { • 1 - النشاط الادبي. }
$$

r ا - المساعدات الاجتماعية.

$$
\text { ع ا - حماية المستهلك. }
$$

1 - الخدمات الدينية والعلمية والثقافية.

$$
\text { ب- رعاية الطفولة والأمومة. }
$$

ه- رعاية الفئات ذات الظروف الخاصة.

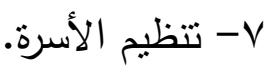

$$
\begin{aligned}
& \text { 9- الإدارة والتظظيم. } \\
& \text { 11 الدفاع الاجتماعي. } \\
& \text { با - الصداقة بين الثعوب. }
\end{aligned}
$$

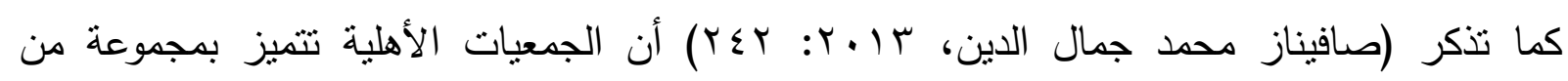
الخصائص ومنها ما يلي: (1) القدرة على التعرف على المجتمع المحلي، وعلى مشكلات واحتياجات سكانه من الخدمات وأوجه الرعاية المختلفة.

(Y) المرونة وسرعة الاستجابة، والقدرة على اتخاذ القرار المناسب وفق المستجدات المجتمعية. (r) التسيق مع الجهات الممانلة أو ذات الصلة المباشرة أو غير المباشرة لتقوية العمل وتدعيم الانفتاح على المنظمات الإقليمية والدولية وبذات المجال لتبادل الخبرات ويحقق مزبد من الاستفادة والتعاون مeجها.

(ع) القدرة على نشر ثقافة حقوق الطفل حيث إن معرفة الأفراد بحقوقه بمكن أن تشكل المرحلة الأولى من أجل الإصرار على نيل هذه الحقوق والعمل بوعي للحصول عليها.

\section{أوجه القصور في الجمعيات والمؤسسات الأهلية الصرية:}

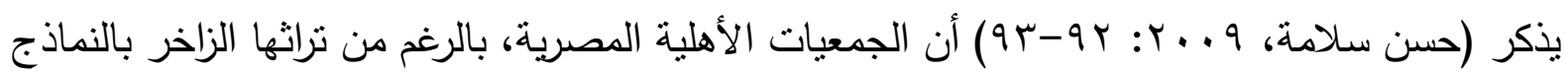
المضيئة والمشرفة منذ أوائل القرن التاسع عشر ودورها الحيوي كثبكة للأمان الاجتماعي، ما زالت تواجه صعوبات وتعاني من مشاكل هيكلية أهمها:

(1) ضعف البناء المؤسسي للجمعيات مما يكرس الثخصانية وغياب الصف الثاني في أغلب الحالات، فتقافة العاملين في الجمعيات الأهلية، هي امتداد لتقاليد وقيم العمل البيروقراطي والإداري الحكومي، 
أما لأن بعضهم يمثل امتدادا لهذه الخبرات التي يحكمها الخوف، والتردد وعدم الإبداع الإداري،

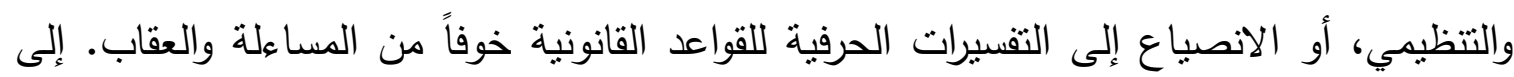
جانب ذلك، فان الميل للخضوع لأوامر وتوجيهات الجهات الإدارية يمنل عائقا أمام مزيد من الإبداع، لا شك أن هذا النمط الثقافي هو أقرب إلى ثقافة الموظف العام البيروقراطي في مصر، منها إلى ثقافة العمل التطوعي القائم على تخصيص جزء من ميزانية الوقت المتاحة للشخص لينهض بأعمال تطوعية.

(Y) مشكلة غياب المهنية تبدو من أبرز الملامح السلبية الآن سيما مع ضعف التقافة المتخصصة في تتشة كادر مدرب وفق التقاليد والمعايير المعروفة في كل تخصص، حيث تبدو الأزمة متفاقمة الآن، ويبدو من الملاحظة العابرة أن برامج التدريب وإعادة التأهيل المهني للعاملين، أمر ينطوي على حلى أداءات استعراضية وشكلية أكثر من كونها برامج ذات مردود إيجابي وفعال على أداء العاملين،

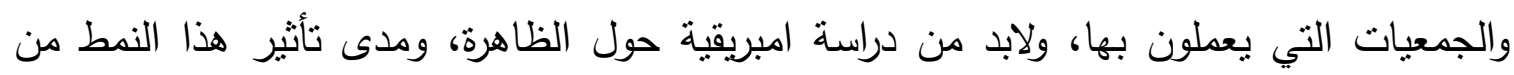
البرامج الممولة من الخارج في الغالب على الأداء المهني للعاملين. (r) صعوبة الحصول على التمويل، وهو ما يثير إثكالية العلاقة بين المنظمات الأهلية والجهات الأجنبية. فمن المسلم به أنه بلا مصادر مالية للإنفاق على أغراضها لا تستطيع المنظمات أو الجمعيات الأهلية أن تعمل، وتعتمد المنظمات الأهلية المصرية الحديثة على المصادر الحكومية من ناحية وعلى التمويل الخارجي من ناحية أخرى.

\section{السؤال الثاني : ما دور الجمعيات والمؤسسات الأهلية في مجال رماية الأثُخاص ذوي الإماقحة}

تعتبر الجهود التطوعية في مجال الرعاية الاجتماعية قديمة ومعاصرة لنشأة المجتمع المصري الحديث، وقد عرف الإنسان بميله للتعاون مما دعاه إلى موازنة جهود غيره من الأفراد، لمواجهة المشاكل التي يتعرضون لها في محاولة لإيجاد الحلول الملائمة. كما جاءت الأديان السماوية فحثت على رعاية المحتاج ومساعدة القادر لغير القادر، والأخذ بيد الضعيف والمريض والمحتاج، كما حثت على التعاون والتكافل الاجتماعي. وفي العصر الحديث نشأ نوع من النشاط الأهلي في كثثر من المجتمعات كان الدافع له دينيًا في بعض الحالات، بل وترفعًا في البعض الآخر من بعض الطبقات الارستقراطية التي أرادت أن تظهر للمجتمع -عن رغبة صادقة أو غير صادقة- أنها لا تقل جدية عن الآخرين في الأخذ

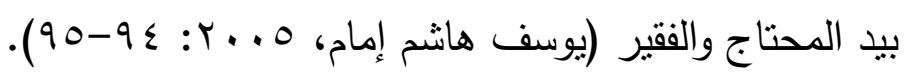

وكان نتيجة صدور القانون 1 ال لسنة .00 (م قيام وزارة الثئون الاجتماعية بإنشاء قسم التأهيل المهني تابعًا للإدارة العامة للمساعدات بمصلحة الضمان الاجتماعية حيث اقتحم الميدان العملي لتاهيل ذوي الإعاقة بافتتاح أول مكتب للتاهيل المهني في مصر حكوميًا، ثم أدمج في جمعية أهلية (مؤسسة 
التأهيل المهني) عام بهو (م، ومنذ ذلك الحين تقام خدمات رعاية وتاهيل ذوي الإعاقة من خلا

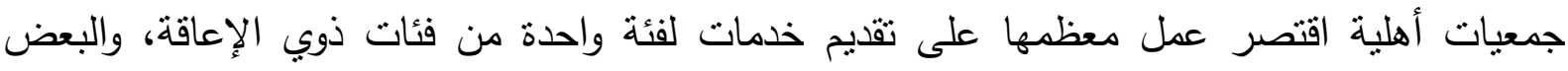

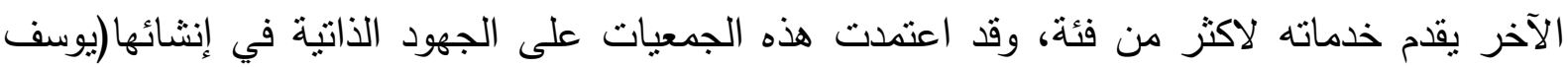

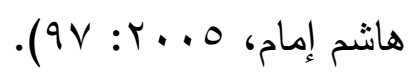

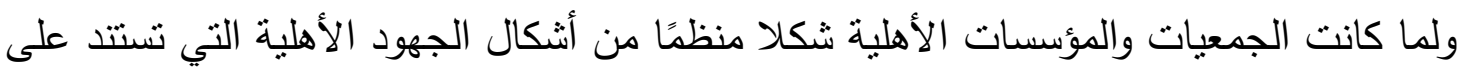

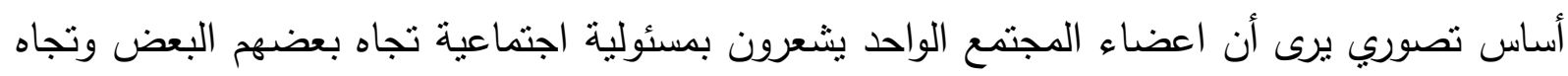

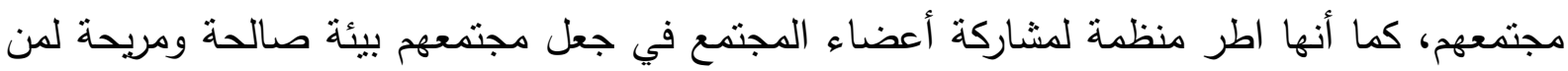

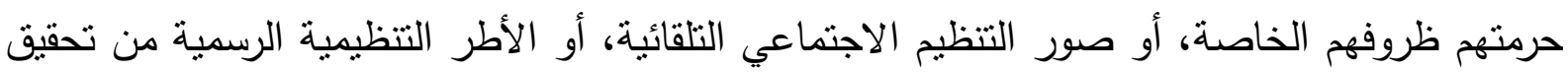

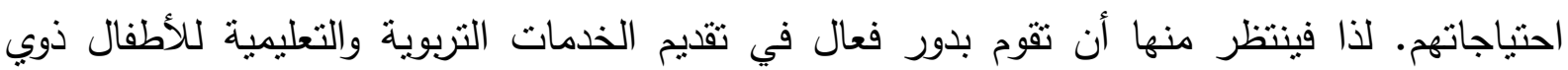

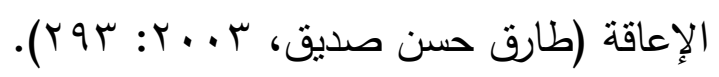

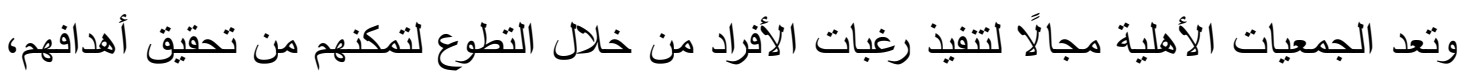

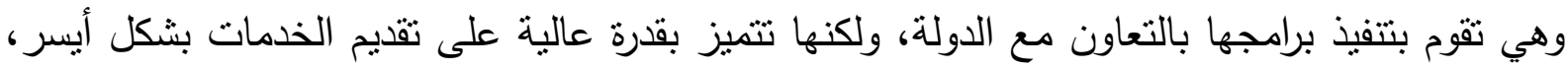

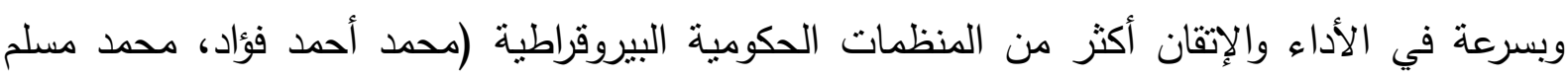

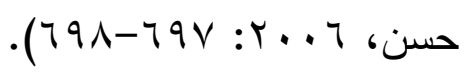

ويذكر (محمود البخيت، r ...r: 0-7) أن الجمعيات والمؤسسات الأهلية تمارس دورها في

رعاية ذوي الإعاقة من خلال المجالات التالية: 1- نوفير الرعاية الصحية والعلاجية وذلك بإنشراف ذوبي الاختصاص.

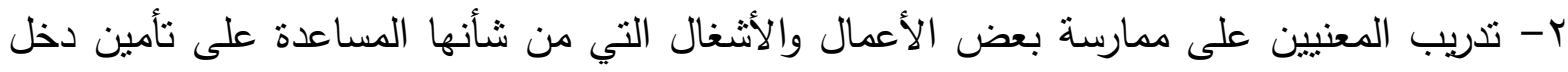
مناسب.

r- توفير الرعاية التقافية والتعليمية من خلال المحاضرات وعقد دورات لمحو الأمية. ع - التأهيل البدني وذلك من خلاد التدريب على ممارسة شؤون الحياة اليومية بشكل طبيعي.

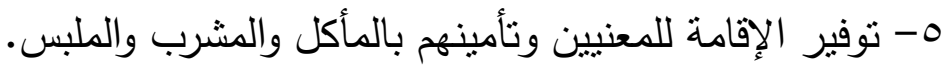
7- تأمين وسائط النقل من وإلى مراكز العناية. V - نوفير الرعاية الاجتماعية والترويحية من خلال النشاطات المتعددة كالرياضة والرحلات.

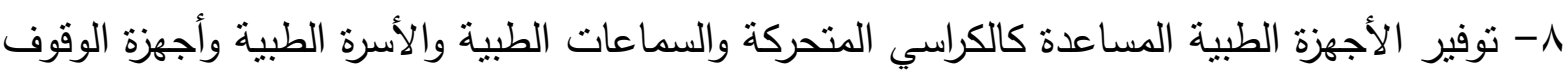
وذلك بالتعاون مع الجهات الحكومية وغيرها من الجهات الداعمة. 9- نتمية القدرات والمهارات الموجودة لدى المنتفعين. 
• ا- العمل على دمج المنتفعين في المجتمع وتهيئة الظروف لهم حتى لا بشعروا بأي غربة عن

$$
\text { المجتمع الذي يعيشون فيه. }
$$

11- إيجاد فرص عمل مناسبة لهم، كل حسب قدرته وطاقته.

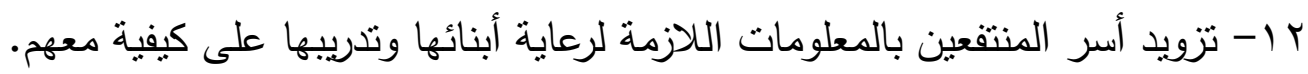

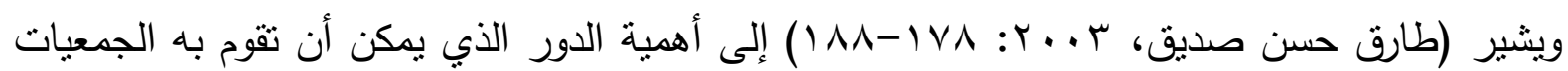

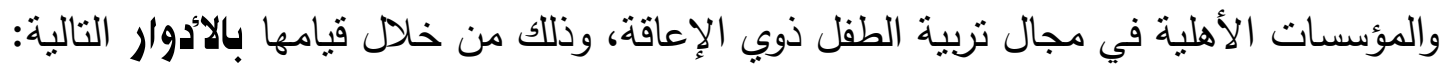

1- العمل على تطبيق مبدأ تكافؤ الفرص التعليمية. r- المطالبة بحقوق الأطفال ذوبي الإعاقة.

r- استثمار الجهود التطوعية للمشاركة في تربية الطفل ذوي الإعاقة.

ع - دعم ومساندة الأسرة في تربية طفلها ذوي الإعاقة.

0- نوعية أفراد المجتمع بأهمية تربية الأطفال ذوي الإعاقة.

צ- مساندة الجهود الحكومية في تربية الطفل ذوبي الإعاقة.

V- الثراكة مع الهيئات والمنظمات العالمية في دعم تربية الطفل ذوبي الإعاقة.

\section{تجارب بعض الجمعيات الأهلية العاملة في مجال روماية ذوي الإعاقة:}

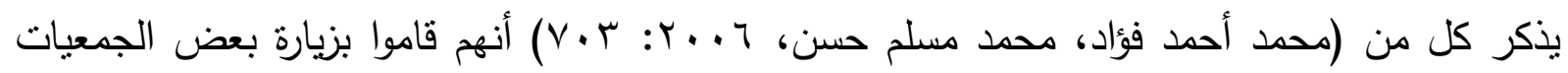

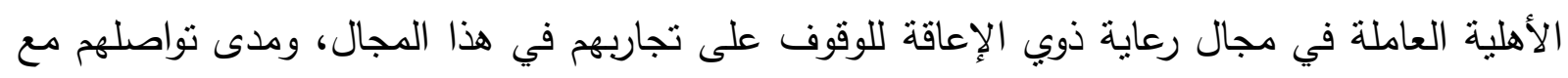

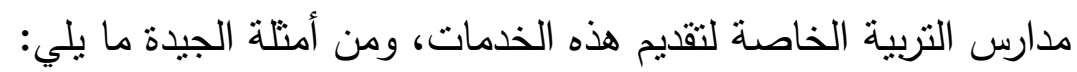

\section{جمعية كاريتاس ومركز سيتي:}

هي جمعية ذات نفع عام ومنتسبة لهيئة كاريناس الدولية، ولها فروع في خمس محافظات هي القاهرة،

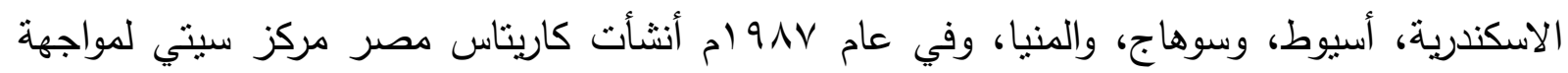
مشكلة نقص الخدمات المتاحة للأشخاص ذوي الإعاقة، بحيث يعمل المركز على تأهيلهر وتمكين أولياء

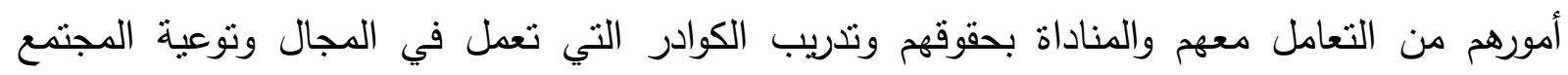
وتعديل اتجاهاته وتفعيل دور المؤسسات القائمة.

\section{(Y) جمعية البسمة الخيرية لذوي الاحتياجات الخاصة وأسرهم بالمنوفية:}

هي جمعية غير هادفة للربح تهدف إلى رعاية الأطفال ذوي الإعاقة وأسرهم وتقديم خدمات تأهيلية واجتماعية وتربوية لهذه الفئة. ومن ميادين عمل الجمعية رعاية الفئات الخاصة وذوبي الإعاقة، ورعاية 
الأسرة والطفولة والأمومة، والمساعدات والخدمات الاجتماعية، والأنثطة التعليمية، والخدمات الثقافية، والعلمية، والدينية، والأنشطة الصحية.

\section{(r) جمعية التأهيل الاجتماعي لرعاية ذوي الاحتياجات الخاصة بالزقازيق:}

هي جمعية أهلية تابعة لوزارة التضامن الاجتماعي (الشئون الاجتماعية سابقًا) غير هادفة للربح، تقدم خدمات ورعاية لذوي الاحتياجات الخاصة من جميع الفئات العمرية، وتقوم بمنح شهادات التأهيل، وميدان عملها جميع الإعاقات المختلفة، ويتبعها (· (1) مكاتب للنأهيل الاجتماعي في مراكز محافظة الشرقية، وتشتمل الجمعية على مركز للعلاج الطبيعي، وورشة تصنيع للأجهزة التعويضية، ومطبعة تقوم بطباعة جميع أنواع المطبوعات لخدمة المجتمع، ومركز لرعاية وتأهيل المكفوفين يتم تدريبهم فيه على الكمبيوتر بطريقة برايل، وغير ذلك، وحضانة للأطفال ذوي الاحتياجات الخاصة من جميع الإعاقات، ووحدة للسمعيات والتخاطب، ومركز للتأهيل المرتكز على المجتمع يقدم للمعاقين الخدمات، وبرامج التوعية والإرشادية والتدريبية لهم ولأسرهم بأماكن إقامتهم، وتسمى بقاقل النور، ومن المشروعات المستقبلية للجمعية إنشاء معهد فني لمنح شهادة دبلوم الدراسات العليا في التربية الخاصة.

ومن الجمعيات الأهلية أيضًا في مجال رعاية ذوي الاحتياجات الخاصة كما يذكر (محمد المري محمد

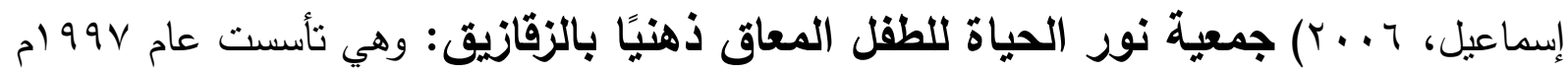
وذلك بموجب عقد تأسيس بمديرية الثئون الاجتماعية، ومن أهم أغراض الجمعية:(استقبال الاطفال المعاقين ذهنيًا على مستوى محافظة الثرقية- ومساعدتهم على التقاعل الاجتماعي- وتقديم الرعاية العقلية والمعرفيه لهم- تأهيلهم بمهنة تتاسب قدراتهم وميولهم- والارشاد النفسي لآسرهم- ودمجهم في المجتمع- وخلق فرص عمل لهم). ويتمثل ميدان عمل الجمعية في: أ- رعاية ذوي الاحتياجات والمعوقين ذهنيًا. ب- خدمات ومساعدات ثقافية وعلمية ودينية وتربوية وصحية. وكان من أهم أنشطة الجمعية طبقًا للائحة الخاصة بها: - إقامة فصول تعليمية وتربوية وتدريسية لهؤلاء الأطفال. - تتظيم حفلات ورحلات ترفيهية وتثقيفية للأطفال وأسرهم والعاملين بهذا المجال. - إقامة معارض تعليمية وتسويقية بالاشتراك مع الجهات المعنية في المجتمع المحلي وتأهيلهم للاندماج - إقامة ندوات ومؤتمرات علمية وثقافية وتربوية تتاقش قضايا هؤلاء الأطفال. - إقامة مستوصف طبي ملحق بالجمعية لتقديم الخدمات الصحية لهم ولأسرهم. 
- دعوة العاملين بالصحافة والإعلام والإذاعة والتلفيزيون للتوعية ونشر الوعي لأسرهم والمجتمع المحيط.

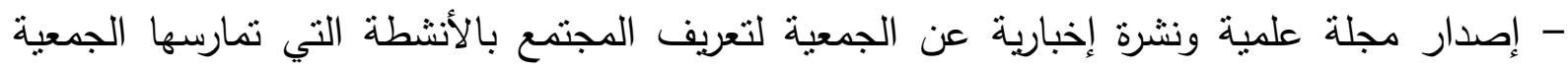
والندوات الني تعقدها.

- إقامة دورات تدريبية لإعداد وتتمية العاملين في هذا المجال مهنيًا. - إقامة دورات إرشادية وتربوية لأسر هؤلاء الأطفال. - العمل على تيسير الحج والعمرة لأسر الأطفال وأعضاء الجمعية.

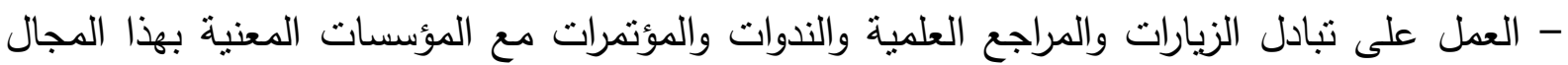
ساء داخل مصر أو خارجها.

\section{وتوجد بعض اللدراسات والبحوث السابقة التي اهتمت بلدور الجمعيات الأهلية في مجال}

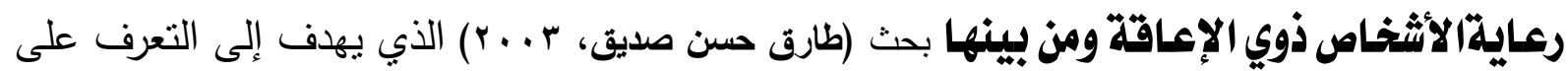

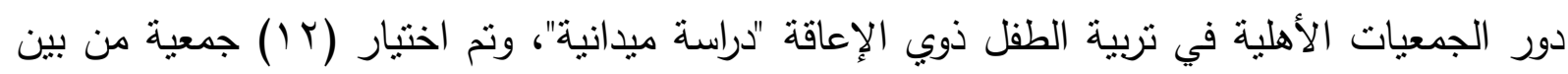

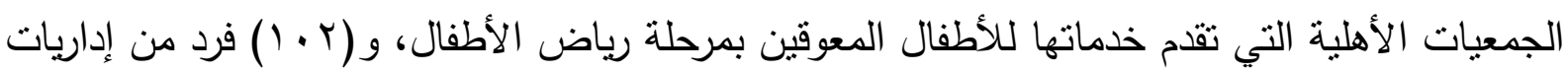

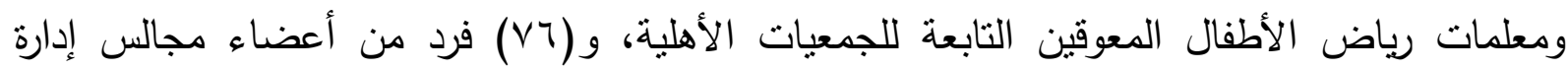
الجمعيات الأهلية والعاملين بها بجمهورية مصر العربية، واقتصرت الدراسة على فئات الأطفال المعوقين

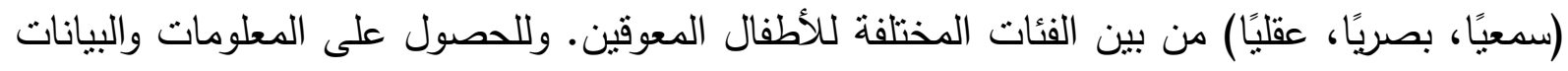

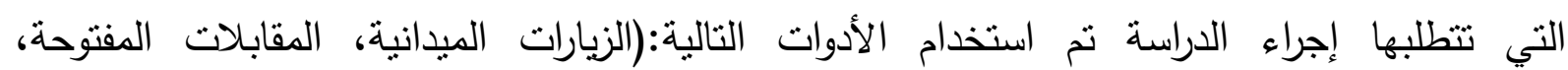

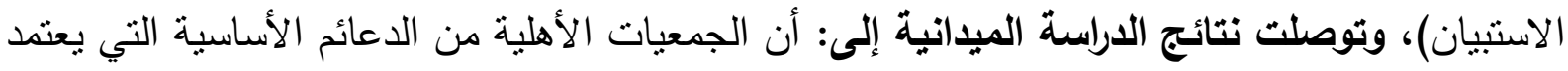

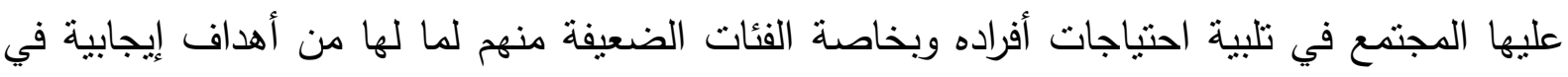
خدمة صالح الأفراد والمجتمع وبما نسهم به وتقدمه من مجهودات تطوعية تقوم على المهارة والخبرة

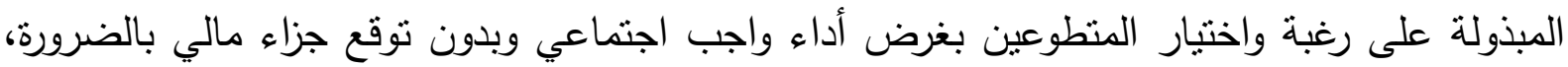

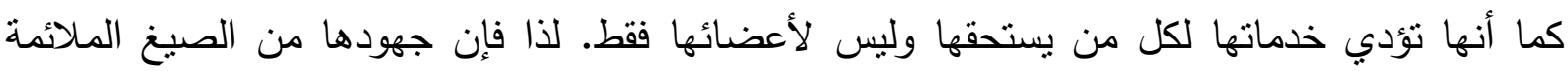
لتوفير الخدمات التربوية التعليمية للأطفال المعوقين لما تتطلبه هذه الخدمات من منطلبات ولات يمكن توفيرها بكفاءة عالية عن طريق جهود هذه الجمعيات.

وأيضًا بحث (محمد أحمد فؤاد، محمد مسلم حسن، ج . . ب) الذي يهذف إلى تفعيل العلاقة بين مدارس

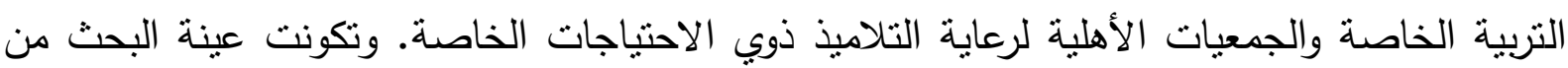

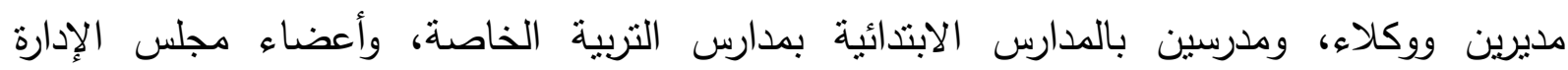

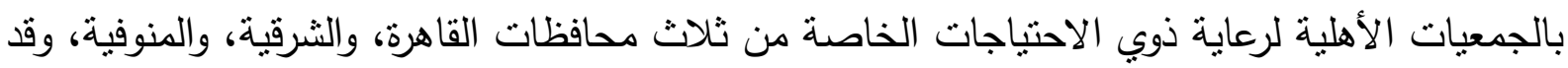

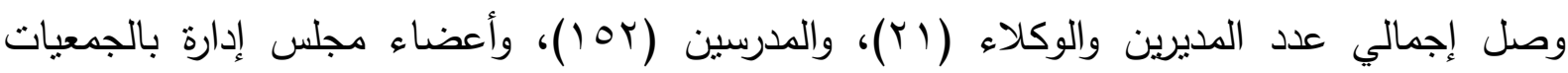


( § 1) فردًا من أعضاء مجلس إدارة (19 1) جمعية بالمحافظات الثلاث. وتم بناء وإعداد الاستبانتين، الأولىى موجهة إلى أعضاء إدارة مدارس التربية الخاصة لمعرفة واقع العلاقة بين مدارسهم والجمعيات

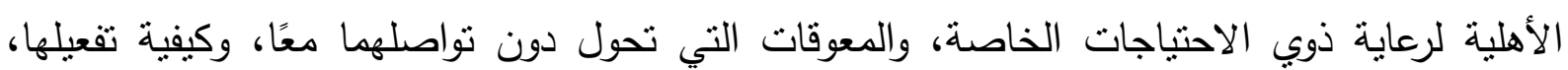
والثانية: موجهة إلى أعضاء مجالس إدارات الجمعيات الأهلية؛ لمعرفة العلاقة بين هذه الجمعيات وتللك المدارس، والمعوقات التي تحول بين التواصل بينهما، وكيفية تفعيل هذه العلاقة. ومن خلال الدراسة الميدانية تم التوصل إلى عدة نتائج أبرزها مايلي:

\section{- نتائج تخص مدارس التربية الخاصة:}

1- وجود إجراءات إدارية شديدة تضعف قنوات الاتصال بالجمعيات الأهلية.

$$
\text { r - غياب مفهوم الثراكة بين المدرسة والجمعيات الأهلية. }
$$

r-ضعف استجابة الخبراء والمتخصصين في المجتمع في أنشطة المدرسة. ع- قلة حرص المدرسة على إتاحة الفرصة للجمعيات لعقد دورات تدريبية على الحرف اليدوية للتناميذ. ه-قلة الزيارات المتبادلة بين المدرسة والجمعيات. 7- ضعف التقة في قدرة الجمعيات على تقديم الدعم للتناميذ. V- ضرورة تمثيل المدارس في اجتماعات الجمعيات الأهلية.

- ونتائج تخص الجمعيات الأهلبة لرعابة ذوي الاحتباجات الخاصة: 1- أهمية الثفافية في كافة تعاملات الجمعية. r- وجود قيود شديدة على تلقي تبرعات من الغير. ب- ضعف انتظام الأعضاء في المشاركة في أنشطة الجمعية. ع - نقص الإمكانات المادية والبشربة المتاحة للجمعيات. 0- أهمية ضم أعضاء جدد للجمعية.

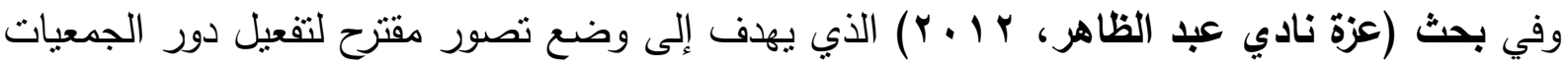
الأهلية المصرية في مجال تأهيل المعوقين حركيًا في ضوء خبرات بعض الدول. فقد اشتملت عينة الدراسة على الأخصائيين النفسيين والمهنيين والأخصائيين الاجتماعيين وأطباء وممرضي التأهيل والمدراء والمحاسبين والسكرتار ية ومسئولي حسابات الجمعيات ومدرسي مشاغل التأهيل والعاملين بدور الحضانة الملحقة بهذه الجمعيات في كل من محافظة الفيوم والقليوبية والمنيا وبلغ عدد أفراد العينة (ror). وتم استخدام استبانة للتعرف من خلالها على دور الجمعيات الأهلية في مجال تأهيل المعوقين حركيا. 


\section{وكثفت الاراسة الميدانية عن مجموعة من النتائج أهمها:}

\section{- وحود مجموعة من المعوقات مرتبطة بالجمعيات الأهلية منها:}

ا- ضعف القدرات الإدارية للجمعيات الأهلية في مصر، فالجمعيات الأهلية تعتمد على نوايا طيبة ومبادرات أهلية جيدة وهذا لا يكفى لمواجهة احتياجات اجتماعية متجددة، بالإضافة إلى غياب الكفاءات الإدارية القادرة على العمل إما من خلا التطوع أو التوظيف. ץ- عدم التسيق بين مؤسسات رعاية وتأهيل الفئات الخاصة وغيرها من المؤسسات المجتمعية الأخرى سواء الأهلية أو الحكومية مما يعوق الاستفادة من الموارد والإمكانيات المادية والبشرية والتنظيمية لتلك المؤسسات في تأهيل تلك الفئات. ץ- عدم وجود نظام تتبعي للتأكد من تكيف واستقرار المعوق في عمله الجديد إن وجد وتغلبه على الحواجز البيئية والمجتمعية. ب- القصور الواضح في البيانات الخاصة بالمعوقين وغياب الإحصاءات والمعلومات اللازمة التي تساعد في التعرف على أبعاد الإعاقات وتزايد أو تتاقص أعداد المعوقين في المجتمع. ع- زيادة الطلب على مؤسسات رعاية وتأهيل الفئات الخاصة وعدم قدرتها على استيعاب جميع المتقدمين لها من تلاك الفئات الذين يزداد عددهم طرديًا كل عام مما يحد من توفير الخدمات للمحتاجين من

\section{- ومعوقات مرتبطة بعملية التأهيل ومنها:}

ا- نقص الموارد المالية ونقص المنشآت الطبية والتعليمية ونقص أفراد التدريب والتأهيل وعدم رغبة الجماهير في التعاون مع الأجهزة القائمة بعملية التأهيل. ץ- عدم تعاون أسرة المعاق مع مؤسسات رعايته مما بنعكس على عمليات تأهيله وصعوبة تكيفه نفسيًا واجتماعيًا لعدم متابعة الأسرة له وشعوره بأنه منبوذ من المجتمع. ب- قضية نقص الكوادر والكفاءات المدربة في بعض مراكز التدربب المهني وبخاصة الإعداد الأكاديمي وقضية تحديث برامج التأهيل المهني إذ أن معظم هذه البرامج تقليدية، وقضية تتغيل الأفراد المدربين في سوق العمل وموقف أصحاب العمل من تشغيل هؤلاء في مؤسساتهم. ع - يتطلب التأهيل إمكانيات مادية هائلة قد لا تتوفر لكثير من المجتمعات وخاصة النامية منها وصعوبة هوتية تحديد مقاييس مقننة تقيس قدرات المعوق سواء عند التأهيل المهني كعملية تستهدف اختيار المهنة المناسبة للفرد وعند التوجيه المهني، كما أن التأهيل هو إعادة تدريب المعوق على مهارة معينة نتاسب قدراته الباقية فهي عملية هجر أمر مألوف إلى أمر آخر غير مألوف مما يؤدي إلى مقاومة المعوق تمشيًا مع النزعة العامة للفرد لمقاومة التغيير • 
ه- قصور بعض أحكام القانون رقم 9 ب لسنة 9 19 ومنها على سبيل المثال المادة الثالثة التى تتص على أن للمعوق الحق في التأهيل ، وتؤدى الدولة خدمات التأهيل دون مقابل وفى حدود المبالغ المدرجة في الميزانية، مع العلم أن الحق في التأهيل كان من المفترض أن يكون مطلقا غير مقيد بحدود الميزانية. ج- النظرة القائمة التى ينظر بها المسئولون في بعض المنشآت للمعوقين الذين تم تأهيلهم، من حيث انخفاض مستوى إنتاجهم وكثرة طلباتهم ومشاكلهم، وفى هذا إهدار لعملية التأهيل في شموليتها، وإثبات عجزها في نأهيل الثخص المعوق حتى يتمكن من الحصول على عمل يستقر فيه. - قصور التأهيل وعجزه عن مسايرة التطور الذي يعرفه سوق العمل من حيث الاحتياجات المهنية ومستويات الكفاءة وهو ما أدى إلى إحجام بعض المؤسسات عن استقبال المعوقين حركيا بدعوى عدم ملائمتهم للمهن المؤهلين لها. 1- تعدد مستويات الهيكل التنظيمي دون الالتزام بوحدة الأمر والتوجيه مما يؤدي إلي تضارب في الرأي تعارض في التوجيه- الأشراف والتوجيه الفني علي المدارس التابعة للجمعيات غير واضح وربما يرجع ذللك إلي كثره جهات الرقابة والأشراف المالي.

9 - عدم وجود أهداف تربوية واضحة للجمعيات تعمل للوصول إليها. • 1 - عزوف بعض الجمعيات والمؤسسات عن المشاركة في الانشطة التعليمية.

\section{السؤال الثالث: ما الرؤية المستقبلية لتفميل دور الجمعيات والمؤسسات الأهلية في مجال رماية

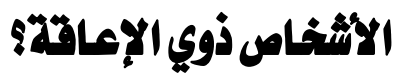

في ضوء ما تم عرضه في هذه الدراسة من تحديد ماهية الجمعيات والمؤسسات الأهلية في مصر، والتعرف على دور الجمعيات والمؤسسات الأهلية في مجال رعاية الأشخاص ذوي الإعاقة من خلال عرض تجاربها والبحوث والدراسات حولها، يمكن الوصول إلى رؤية مستقبلية لتفعيل دور تلك الجمعيات والمؤسسات الأهلية في مجال رعاية الأشخاص ذوي الإعاقة من خلال ما يلي: ا - تتظيم دورات تدريبية للأخصائيين الاجتماعيين والعاملين بالجمعيات الأهلية على أسلوب التعامل مع الأشخاص ذوي الإعاقة.

ץ- توضيح الأهداف الحقيقية التي تسعى الجمعيات والمؤسسات الأهلية إلى تحقيقها. ب- الاهتمام بوسائل الاتصال الحديثة بين الجمعيات والمؤسسات الأهلية والتعاون المثر بينهم في تبادل الآراء والأفكار والخبرات والبرامج والخطط والمشروعات المشتركة بينهم. ع - تقوية الترابط ودعم العلاقات بين الجمعيات والمؤسسات الأهلية والتتسيق في الخدمات للأشخاص ذوي الإعاقة. 
ه- تبادل الخبرات بين الجمعيات والمؤسسات الأهلية المحلية والدولية والاشتراك في المؤنمرات العالمية والعربية وورش العمل للاستفادة من خبراتهم في مجال تقديم الخدمات للأشخاص ذوي الإعاقة. צ- إنشاء مركز معلومات عن الجمعيات والمؤسسات الأهلية في المجتمع ووجود قاعدة للبيانات والمعلومات الخاصة بهم، وعمل شبكة ربط بينهم وبخاصة الجمعات العاملة في مجال رعاية الأشخاص ذوي الإعاقة. - استثمار وسائل الإعلام والحث على المشاركة التطوعية والتواصل بين الجمعيات والمؤسسات للتعرف على احتياجات ومشاكل الأشخاص ذوي الإعاقة ووضع خطط تتموية مشتركة بينهم. 1- زيادة عدد الأخصائيين الاجتماعين والنفسيين والتخصصات المختلفة داخل الجمعيات الأهلية الخاصة بالأشخاص ذوي الإعاقة. و- زيادة موارد الجمعية المالية لتتمكن من المساهمة في تحمل نفقات الأثخاص ذوي الإعاقة في توفير احتياجاتهم. • 1- نشجيع مشاركة الشباب في أنشطة الجمعية التطوعية. الـ رفع القيود التي تعيق دور الجمعيات والمؤسسات الأهلية العاملة في مجال رعاية الأشخاص ذوي الإعاقة وتبني فلسفة ديمقراطية تؤمنهم حق المشاركة واتخاذ القرار • r ا - تحديث الجمعيات والمؤسسات الأهلية بالوسائل التكنولوجية الحديثة من أجل زيادة الاستفادة التي يحصل عليها الأشخاص ذوبي الإعاقة من تدريبهم وتأهيلهم داخل الجمعية. r ا - أن تقدم الجمعيات والمؤسسات الأهلية دورات تدريبية لأسر الأشخاص ذوي الإعاقة ولأفراد المجتمع المحلي عن كيفية التعامل الصحيح مع أبنائهم من المعوقين. ء ا - نشر كتيات ومنشورات عن أهداف الجمعية وأنشطتها وبرامجها وتقديمها لأولياء الأمور وبخاصة

$$
\text { في مجال رعاية الأشخاص ذوي الإعاقة. }
$$

0 ד ا - ضرورة أن تشاهم الجمعيات والمؤسسات الأهلية بدورًا فاعلًا في العمل على الوقاية من الإعاقة من خلال إرشاد المقبلين على الزواج وتتظيم برامج للعناية بالأم الحامل إلى جانب المشاركة في حملات تطعيم الأطفال. IV - المشاركة في إجراء المسوح الميدانية والدراسات الإحصائية لتجميع المعلومات حول الإعاقة ومدى التى انتشارها وطبيعتها وخصائصها الديموغرافية والأساليب والتسهيلات المتاحة للوقاية منها، مع اهمية التزكيز على المناطق النائية والفقيرة. 1 ا- ضرورة أن تساهم الجمعيات والمؤسسات الأهلية على توفير بيئة أسرية تكفل إثباع الحاجات الأساسية للطفل ذوي الإعاقة ، مع تقديم الدعم المادي والاجتماعي والنفسي لهذه الأسر • 
9 ا - دعوة القادة والمسئولين ورجال الأعمال إلى الإسهام الإيجابي في تحمل المسئولية الاجنماعية ومساندة الجمعيات والمؤسسات الأهلية العاملة في مجال رعاية الأطفال ذوي الإعاقة بالقكر والجهد

$$
\text { والمال في قبامها بمسئولياتها. }
$$

• ץ- ضرورة أن تعمل الجمعيات والمؤسسات الأهلية العاملة في مجال رعاية الأطفال ذوي الإعاقة على تدعيم صلتها بالمنظمات والهيئات الدولية المعنية (اليونيسيف- اليونسكو - منظمة الصحة العالمية- الاتحاد الدولي لرعاية الطفولة- الاتحاد العالمي للمعوقين- الاتحاد العربي للصم والبكم....)، بما يتيح لها الوقوف على الاتجاهات والأساليب الحديثة في تقديم الخدمات التربوية للأطفال ذوي الإعاقة وتطوير الأنشطة والبرامج الخاصة بذلك. اب- ضرورة أن تعمل الجمعيات والمؤسسات الأهلية على تتظيم المؤتمرات المحلية والإقليمية والبرامج والحلقات الدراسية والندوات التي تعرض فيها مشكلات الأطفال ذوي الإعاقة والآثار المترتبة على إهمال هذه الفئات بالتعاون مع جهة ومسئولي التربية الخاصة لتبادل الخبرات وإثراء العمل وبخاصة

$$
\text { التطوعي منه. }
$$

r ب- العمل على زيادة الدعم المالي الحكومي للجمعيات والمؤسسات الأهلية، وتسهيل أمر حصولها على

$$
\text { موارد مالية ذاتية، دون تعقيدات إدارية. }
$$

\section{(1)}

حسن سلامة (9 . . r). الجمعيات الأهلية ودور رأس المال الاجتماعي. الايمقراطية، السنة التاسعة،

$$
\text { العدد (0)، ص ص ص (10 (10-1079. }
$$

زينب صالح الأشوح ( (. . ب). دور المنظمات الاجنماعية الأهلية في مجالات التتمية البشرية في مصر "دراسة تطبيقية على مؤسسة المدينة المنورة الخيرية للبر والخدمات الاجتماعية". مجلة مركز صالح عبد الله كامل للاقتصاد الإسلامي، جامعة الأزهر، العدد (1)، ص ص ( (1) • V. 
سميرة إبراهيم الدسوقي محمد (• ( (Y). تقدير حاجات متعددي الإعاقة في برامج الرعاية الاجتماعية بالجمعيات الأهلية. دراسات في الخدمة الاجتماعية والعلوم الإنسانية، ص ص 0 صـ. $. r \| r$

صافيناز محمد جمال الدين عبد المنصف (ب( ب). دور الجمعيات الأهلية في دعم حقوق الأطفال المعرضين للخطر • المؤتمر الدولي الرابع "اليوم أمل الغد"، كلية رياض الأطفال، جامعة

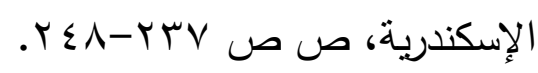

صبحي شعبان (ع9 (1). الإسهامات التربوية للجمعيات الأهلية بمحافظة المنوفية "دراسة وصفية

تقومية". رسالة ماجستير (غير منشورة)، كلية التربية، جامعة المنوفية.

طارق حسن صديق سلطان (ץ . . r). دور الجمعيات الأهلية في تربية الطفل المعوق "دراسة مبدانية".

$$
\text { رسالة ماجستير (غير منشورة)، كلية التربية، جامعة جنوب الوادي. }
$$

عزة نادي عبد الظاهر عبد الباقي (Y (. Y). تصور مقترح لتفعيل دور الجمعيات الأهلية المصرية في مجال تأهيل المعوقين حركيًا في ضوء خبرات بعض الدول. رسالة ماجستير (غير منشورة)، كلية التربية، جامعة الفيوم.

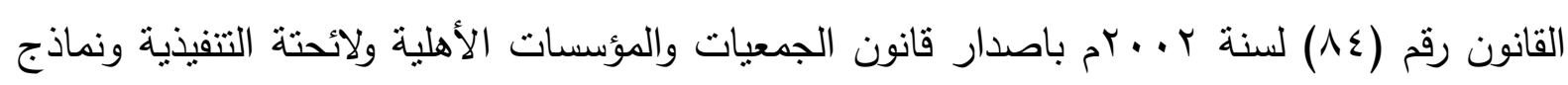
السجلات. مركز معلومات الاتحاد الاقليمي للجمعيات والمؤسسات الأهلية بالثرقية، محافظة الثرقية، مطبعة مؤسسة تربية البنين ملجأ الأيتام. محمد أحمد فؤاد مرغني، محمد مسلم حسن علي (T . . Y). تفعيل العلاقة بين مدارس التربية الخاصة والجمعيات الأهلية لرعاية التلاميذ ذوي الاحتياجات الخاصة. المؤتمر العلمي الرابع "دور الأسرة ومؤسسات المجتمع المدني في اكتشاف ورعاية ذوي الاحتياجات الخاصة"، الفترة

$$
\text { (r) }
$$

محمد المري محمد إسماعيل (T . . ץ). تقرير عن جمعية نور الحياة للطفل المعاق ذهنيًا بالزقازيق. المؤتمر العلمي الرابع "دور الأسرة ومؤسسات المجتمع المدني في اكتثاف ورعاية ذوي الاحتياجات الخاصة"، القترة (ب-ع ) مايو، كلية التربية، جامعة بني سوبف. 
دور الجمعيات وإلمؤسسات الأهلية في مجال رعاية الأثخاص ذوي الإعاقة

محمود البخيت (r . .ب). الجمعيات الخيرية ودورها في رعاية ذوي الإعاقة دن وجهة نظر الإسلام. المؤتمر العلمي لرعاية ذوي الحاجات الخاصة في الاسلام، جامعة جرش، كلية الثريعة، الأردن.

مرفت احمد محمد ابو النيل (r ( ب r). منطلبات تدعيم التكامل بين الجمعيات الأهلية العاملة في مجال رعاية المعاقين من منظور الممارسة العامة للخدمة الاجتماعية. "المؤتمر الدولي الخامس والعشرون لكلية الخدمة الإجتماعية بجامعة حلوان ( مستقبل الخدمة الإجتماعية في ظل الاولة المدنية الحديثة ). يوسف هاشم إمام (0. . ب). دور الجهود الأهلية والتطوعية في رعاية ذوي الاحتياجات الخاصة بجمهورية مصر العربية. ورقة عمل مقدمة للمؤتمر العلمي السنوي الثالث عشر بعنوان:"التربية وآفاق جديدة في تعليم ورعاية ذوي الاحتياجات الخاصة "المعاقون والموهويون" في الوطن العربي، في الفترة من با -ـ ا مارس، جامعة حلوان. 